Published in final edited form as:

Thromb Res. 2014 January ; 133(1): 108-111. doi:10.1016/j.thromres.2013.10.035.

\title{
Differences in Thrombotic Risk Factors in Black and White Women with Adverse Pregnancy Outcome
}

\author{
Claire S. Philipp ${ }^{\mathrm{a},{ }^{,}}$, Ambarina S. Faiz ${ }^{\mathrm{a}}$, Michele G. Beckman ${ }^{\mathrm{b}}$, Althea Grant ${ }^{\mathrm{b}}$, Paula L. \\ Bockenstedt $^{c}$, John A. Heit ${ }^{d}$, Andra H. James ${ }^{e, 1}$, Roshni Kulkarni ${ }^{f}$, Marilyn J. Manco- \\ Johnson $^{\mathrm{g}}$, Stephan Moll ${ }^{\mathrm{h}}$, and Thomas L. Ortel ${ }^{\mathrm{i}}$ \\ aDepartment of Medicine, Rutgers Robert Wood Johnson Medical School, New Brunswick, NJ, \\ USA \\ bDivision of Blood Disorders, Centers for Disease Control and Prevention, Atlanta, GA, USA \\ 'Department of Medicine, University of Michigan, Ann Arbor, MI, USA \\ ${ }^{\mathrm{d} D i v i s i o n}$ of Cardiovascular Diseases, Mayo Clinic, Rochester, MN, USA \\ eDepartment of Obstetrics and Gynecology, Duke University, Durham, NC, USA \\ fDepartment of Pediatrics and Human Development, Michigan State University, East Lansing, MI, \\ USA \\ 9Department of Pediatrics, University of Colorado, Denver and the Children's Hospital, Aurora, \\ CO, USA \\ hDepartment of Medicine, University of North Carolina, Chapel Hill, NC, USA \\ 'Departments of Medicine and Pathology, Duke University, Durham, NC, USA
}

\section{Abstract}

\begin{abstract}
Introduction-Black women have an increased risk of adverse pregnancy outcomes and the characteristics of thrombotic risk factors in this population are unknown. The objective of this study was to examine the racial differences in thrombotic risk factors among women with adverse pregnancy outcomes.
\end{abstract}

Methods-Uniform data were collected in women with adverse pregnancy outcomes (pregnancy losses, intrauterine growth restriction (IUGR), prematurity, placental abruption and preeclampsia) referred to Thrombosis Network Centers funded by the Centers for Disease Control and Prevention (CDC).

\footnotetext{
Disclaimer: The findings and conclusions in this report are those of the authors and do not necessarily represent the views of the Centers for Disease Control and Prevention.

(c) 2013 Elsevier Ltd. All rights reserved.

"Corresponding author at: Division of Hematology, MEB Rm 378, Rutgers Robert Wood Johnson Medical School, New Brunswick, NJ 08903. Tel.: +1 732235 7682. philipp@ rutgers.edu (C.S. Philipp).

${ }^{1}$ Current affiliation: University of Virginia, Charlottesville, Virginia.

Conflict of interest statement

None declared
} 
Results-Among 343 white and 66 black women seen for adverse pregnancy outcomes, protein $\mathrm{S}$ and antithrombin deficiencies were more common in black women. The prevalence of diagnosed thrombophilia was higher among whites compared to blacks largely due to Factor $\mathrm{V}$ Leiden mutation. The prevalence of a personal history of venous thromboembolism (VTE) did not differ significantly by race. A family history of VTE, thrombophilia, and stroke or myocardial infarction (MI) was higher among whites. Black women had a higher body mass index, and a higher prevalence of hypertension, while the prevalence of sickle cell disease was approximately 27 fold higher compared to the general US black population.

Conclusions-Thrombotic risk factors differ significantly in white and black women with adverse pregnancy outcomes. Such differences highlight the importance of considering race separately when assessing thrombotic risk factors for adverse pregnancy outcomes.

\section{Keywords}

Thrombotic risk factors; thrombophilia; adverse pregnancy outcomes; racial disparities

\section{Introduction}

There are significant disparities in rates of adverse pregnancy outcomes between black and white women [1]. In the US, 69\% of pregnancies among white women end in live birth compared to $49 \%$ of pregnancies in black women [1], and black women have increased rates of fetal loss compared to white women (11.13 vs 4.79 per 1000 live births) [2]. A multicenter US study limited to women with early access to prenatal care reported an approximately 3-4 fold increased risk of both early and late fetal demise in black women compared to white women after adjusting for multiple maternal and socioeconomic characteristics [3]. In addition, significantly higher rates of intrauterine growth restriction, preeclampsia, preterm birth, and placental abruption have been found in black women compared to white women [2,3]. Despite improvements in obstetric care, major racial disparities in adverse pregnancy outcomes persist and remain unexplained.

Thrombotic risk factors have been associated with pregnancy complications [4-8]. Many previous studies have found an association between inherited thrombophilia and adverse pregnancy outcomes, however there has been wide variability in the strength of the association and some studies have not found a relationship [4,6-12]. Despite significant racial disparities in rates of adverse pregnancy outcomes, most studies examining the relationship of thrombotic risk factors in women with adverse pregnancy outcomes have been performed in white populations, and have focused on Factor V Leiden and prothrombin gene mutations [9-12], thrombotic risk factors known to be less prevalent among black populations $[13,14]$. There is very limited information on thrombophilia and other thrombotic risk factors in black women with adverse pregnancy outcomes. The objective of this study was to compare the characteristics of thrombotic risk factors among black and white women with adverse pregnancy outcomes receiving care and participating in a multisite registry at US Thrombosis Network Centers. 


\section{Methods}

Consecutive patients seen in consultation at any of the Thrombosis and Hemostasis

Research and Prevention Network Centers, funded by the Centers for Disease Control and Prevention (CDC), were approached for participation in a patient registry regardless of the reason for their visit, age, sex, or race. After obtaining informed consent, a standardized data collection form was completed by center staff during initial and subsequent visits. Uniform data were prospectively collected from August 2003 to March 2011 and were entered into a web-based registry housed at the CDC, Division of Blood Disorders. De-identified data were submitted by unique patient study identification number. Institutional Review Board approval was obtained at each of the network centers and the CDC and continuing approval obtained annually. Information for the patient registry was collected by network center medical providers at the time of the visit and included demographic and clinical characteristics, concurrent medical conditions, family history, laboratory and radiologic tests, diagnosis, and treatments prescribed. The CDC funded Thrombosis Network Centers and registry have been previously described [15-17].

To examine the prevalence of thrombotic risk factors in women with adverse pregnancy outcomes, we searched the patient registry for women age 15 years and older at enrollment who had been referred to one of the Thrombosis and Hemostasis Network Centers for prepregnancy, pregnancy, or postpartum consultation. From this group of women, we included only women seen for adverse pregnancy outcomes. We further restricted analysis to women of black or white race and compared thrombotic and clinical characteristics between the two racial groups.

Adverse pregnancy outcomes were defined as a documented history of pregnancy loss or losses, intrauterine growth restriction (IUGR), preterm delivery, placental abruption and/or preeclampsia. Race was self-identified. Those who selected more than one race were categorized as "other" race and included in the "other" race subgroup. In addition to individuals selecting more than one race, the "other" race category also included Asians, American Indian, Alaskan native, and Pacific Islanders. The "other" racial category was not included in the data analyzed.

The registry included a history of medical comorbidites including diabetes, hypertension, sickle cell disease, cancer, myocardial infarction and stroke for each woman. The history and clinical presentation of diagnosed thromboembolic events, locations of thrombi, and associated risks such as surgery, trauma, contraceptive use, and hormonal replacement therapy were also collected. Self-reported family histories of thromboembolism, adverse pregnancy outcomes, and diagnosed thrombophilia were also obtained. Medical comorbidities, thromboembolic events, associated thrombotic risk, and family history were compared between the two racial groups.

For this study, thrombophilia was defined as factor V Leiden or prothrombin G20210A mutations, deficiency of antithrombin, protein $\mathrm{C}$, or protein $\mathrm{S}$, or antiphospholipid antibody syndrome (APS) at enrollment or by evaluation by the Center. For most diagnoses made prior to evaluation at the center, the thrombophilia diagnosis was confirmed by testing 
performed on-site at the network centers. The diagnosis of APS was based on the Sapporo classification [18].

A history of venous thromboembolism (VTE) was defined as VTE diagnosed by venography, angiography, duplex ultrasonography, impedence plethysmography, computed tomographic venography or angiography, MRI, or high probability ventilation perfusion scan.

The prevalence of a.priori selected demographic and clinical characteristics were calculated and compared between blacks and whites. For categorical variables Pearson's chi-square test was used and in the case of small cell sizes $(<5)$ Fisher's exact $p$ values were reported. The prevalence of protein $S$ deficiency was also evaluated in the subgroup of women who were not known to be pregnant at the time of study enrollment. Mean values were computed for the continuous variables of age and body mass index (BMI) at the time of enrollment and differences between the racial groups were assessed using Student's t-test. A p-value $<0.05$ was considered statistically significant for the analyses. The data were analyzed using SAS statistical package version 9.2(SAS Institute, Cary, NC).

\section{Results}

Between August 2003 and March 2011, 833 women, (631 white, 152 black, and 50 of other or missing race) were referred to a participating Network Center for pregnancy, prepregnancy, or postpartum consultation or management and enrolled into the patient registry. The mean age at enrollment was $34.8 \pm 10.5$ years. Of these 833 women, 434 were seen for a history of adverse pregnancy outcome ( 343 white, 66 black, and 25 of other or missing races). The adverse pregnancy outcomes included pregnancy loss or recurrent losses, IUGR, preterm delivery, preeclampsia, and placental abruption.

Among the 409 women of black or white race with an adverse pregnancy outcome, the mean age at enrollment was $39.1 \pm 11.8$ years and $33.8 \pm 10.4$ years for white and black women respectively ( $\mathrm{p}<0.01)$. The average body mass index (BMI) at enrollment was higher (31.9 \pm 9.6 vs $\left.29.1 \pm 11.1 \mathrm{~kg} / \mathrm{m}^{2}, \mathrm{p}=0.07\right)$ in black women and the prevalence of non-pregnant BMI $\geq 25$ was significantly higher in black women than white women $(86.2 \%$ vs $63.4 \%, p=$ 0.01 ) (Table 1). The adverse pregnancy outcomes did not differ significantly by race except for second trimester loss, which was more common among black women (33.3\% vs $21.9 \%$, $\mathrm{p}=0.05)($ Table 2).

The prevalence of diagnosed thrombophilia differed by race. Overall, thrombophilia was more common in white women with adverse pregnancy outcomes compared to black women ( $44 \%$ vs $30.3 \%, p=0.04)$ (Table 3 ), although this difference was primarily due to the difference in factor V Leiden mutation (19\% vs 3\%, $\mathrm{p}<0.01)$. However, protein $\mathrm{S}$ deficiency was significantly more common in black women ( $15.2 \%$ vs $5.8 \%, \mathrm{p}=0.02)$ (Table 3). When assessed among the subgroup of women who were not pregnant at study enrollment ( 252 white and 32 black), protein $\mathrm{S}$ deficiency was still more common in black women but the difference did not reach statistical significance $(13.5 \%$ vs $5.5 \%, \mathrm{p}=0.08)$. None of the women with protein S deficiency had sickle cell disease, renal disease, or HIV. 
Antithrombin deficiency was also more common among black women $(6 \%$ vs $1.5 \%, \mathrm{p}=$ 0.04). There were no racial differences in the frequency of laboratory testing for protein $\mathrm{S}$ or antithrombin.

A personal history of VTE, including pulmonary embolism and/or deep vein thrombosis, did not differ significantly by race except for surgery associated VTE which was significantly more common in white women ( $10.8 \%$ vs $1.5 \%, \mathrm{p}=0.02)$ (Table 4). Hypertension $(25.8 \%$ vs $11.4 \%, \mathrm{p}<0.01)$ and sickle cell disease $(4.6 \%$ vs $0 \mathrm{p}<0.01)$ were more common among black women than white women with adverse pregnancy outcomes (Table 5). A family history of VTE $(21.6 \%$ vs 7.6, p < 0.01), and stroke or MI (11.7 vs $0 \%, \mathrm{p}<0.01)$ was more common in white women with adverse pregnancy outcomes than in black women. A family history of thrombophilia was also more common in white women, but did not reach statistical significance $(5.8 \%$ vs $0 \%, \mathrm{p}=0.06$ ), There were no racial differences in family history of adverse pregnancy outcomes (Table 6).

\section{Discussion}

It has been hypothesized that a prothrombotic state may lead to disturbances in uteroplacental circulation resulting in infarction and placental insufficiency which leads to fetal loss and other pregnancy complications $[19,20]$. This has led to frequent thrombophilia evaluations and anticoagulant management to prevent fetal loss and other pregnancy complications. Despite a higher risk of morbidity and mortality in black women and a higher risk of fetal loss, thrombotic risk factors are poorly described in black women. The current study demonstrates racial differences in demographic and clinical characteristics of women with adverse pregnancy outcomes evaluated in US thrombosis centers. Among women with adverse pregnancy outcomes, black women were more likely to have medical comorbidities including hypertension and sickle cell disease, more likely to have protein $\mathrm{S}$ and antithrombin deficiencies, but overall less likely to have an underlying thrombophilia than white women. In addition, black women were less likely to report a family history of VTE or thrombophilia than white women. In this group of black women with adverse pregnancy outcomes, we observed an approximately 27 fold increase in the prevalence of sickle cell disease based on prevalence estimates of 1 in 600 in the general US black population [21], suggesting the potential importance of this risk factor.

Protein $\mathrm{S}$ and antithrombin deficiencies have been associated with pregnancy loss $[4,6,9,10,22,23]$. Our data showed Protein S deficiency to be significantly more common among black women with adverse pregnancy outcomes. This difference in protein $\mathrm{S}$ deficiency between black and white women could not be explained by pregnancy status, or by differences in acquired conditions known to be associated with protein S deficiency such as sickle cell disease, renal disease, or HIV status; other as yet, unknown acquired etiologies of protein $\mathrm{S}$ deficiency among black women cannot be excluded. Our study also found more frequent antithrombin deficiency among black women. Further studies are required to confirm our observed increased prevalence of protein $\mathrm{S}$ and antithrombin deficiencies in black women with adverse pregnancy outcomes. 
We observed a higher prevalence of family history of thrombophilia, VTE, and stroke or MI in white women with adverse pregnancy outcomes suggesting a possible increased role for heredity among white women. However, a personal history of VTE, MI and stroke did not differ significantly by race in the present study.

White women participating in this study were older than black women, reflecting the demographics of pregnancy in the two groups [1]. Since advanced maternal age has been shown to be a risk factor for early miscarriage [24], differences in mean maternal age in the two groups may confound other racial differences. In addition, obesity is a risk for fetal loss, and in this study, blacks were found to have higher BMI, possibly confounding other racial differences. History of smoking is another thrombotic risk factor associated with adverse pregnancy outcomes, however there were no significant differences in smoking history between the racial groups. Our study design did not allow us to adjust for confounding factors. Further studies, with an appropriate comparison group are required to evaluate the racial differences in thrombotic risk factors after controlling for potential confounding factors such as maternal risk factors, and pregnancy complications.

There are limited data on the role of ethnicity and race on the relationship of thrombophilia and other thrombotic risk factors with adverse pregnancy outcomes. Black women with pregnancy complications were included in two US studies, with one limited to Factor V Leiden mutation [25] and one to prothrombin gene mutation [26]. One metaanalysis evaluated the confounding influence of ethnicity on the relationship of factor V Leiden and adverse pregnancy outcomes [12] and included one study in black South African women with pre-eclampsia [27]. Given the paucity of data on the role of race in the relationship of adverse pregnancy outcomes with other thrombophilias, our findings warrant additional confirmatory studies.

Our study has several limitations including a potential referral bias of women with adverse pregnancy outcomes to thrombosis referral centers and limited sample size. The characteristics of the two racial groups referred to thrombosis centers may not accurately reflect the characteristics of their respective populations in general or high risk obstetrics and gynecology settings. However given the multiple participating centers across the US, the study population probably does reflect the referred population seen by thrombosis specialists and other hematologists in the US. The groups differed with respect to age. Some of the differences in thrombotic risk factors such as a history of surgery may have been partly a reflection of the age of the subjects. In addition, given that approximately $90 \%$ of cases of adverse pregnancy outcomes were pregnancy losses, conclusions about other adverse pregnancy outcomes such as placenta abruption, IUGR, and preeclampsia may be less certain. One additional limitation is that the presence of sickle cell trait was not systematically collected, which may be relevant given the high prevalence of sickle cell disease observed in this population of black women with adverse pregnancy outcomes.

Whether testing for thrombophilia should be performed in the evaluation of adverse pregnancy outcomes, which tests for inherited or acquired thrombophilia should be performed, and under what circumstances these tests should be ordered has evolved [28,29]. Nevertheless thrombophilia testing and subsequent pregnancy management with 
anticoagulants has been common clinical practice in this population. This multi-center study suggests the potential importance of race in examining the role of thrombotic risk factors in adverse pregnancy outcomes. The results have potential implications in the identification of risk factors and the development of interventions for the prevention of adverse pregnancy outcomes in racially diverse and non-white populations.

\section{Acknowledgements}

This work was supported by grants from the Centers for Disease Control and Prevention (DD000017 to CP, DD000235 to JAH, DD000016 to MMJ, DD000292 to SM, DD000014 to TLO, and DD000015 to the Hemophilia Foundation of Michigan [PLB, RK]).

\section{References}

1. Ventura, SJ.; Curtin, SC.; Abma, JC. National vital statistics reports. Vol. 60. National Center for Health Statistics; 2012. Estimated pregnancy rates and rates of pregnancy outcomes for the United States, 1990-2008; p. 1-20.

2. MacDorman MF. Race and ethnic disparities in fetal mortality, preterm birth, and infant mortality in the United States: an overview. Semin Perinatol. 2011; 35:200-208. [PubMed: 21798400]

3. Healy AJ, Malone FD, Sullivan LM, Porter F, Luthy DA, Comstock CH, et al. Early access to prenatal care: implications for racial disparity in perinatal mortality. Obstet Gynecol. 2006; 107(3): 625-631. [PubMed: 16507934]

4. Kujovich JL. Thrombophilia and pregnancy complications. Am J Obstet Gynecol. 2004; 191:412424. [PubMed: 15343215]

5. Lockshin MD. Pregnancy loss in the antiphospholipid syndrome. Thromb Haemost. 1999; 82:641648. [PubMed: 10605762]

6. Preston FE, Rosendaal FR, Walker ID, Briet E, Berntorp E, Conard J, et al. Increased fetal loss in women with heritable thrombophilia. Lancet. 1996; 348:913-916. [PubMed: 8843809]

7. Pabinger I. Thrombophilia and its impact on pregnancy. Thromb Res. 2009; (Suppl. 3):S16-S21. [PubMed: 19203641]

8. Lykke JA, Bare LA, Olsen J, Lagier R, Arellano AR, Tong C, et al. Thrombophilias and adverse pregnancy outcomes: results from the Danish National Birth Cohort. J Thromb Haemost. 2012; 10:1320-1325. [PubMed: 22578003]

9. Robertson L, Wu O, Langhorne P, Twaddle S, Clark P, Lowe GDO, et al. Thrombophilia in pregnancy: a systematic review. Br J Haematol. 2005; 132:171-196. [PubMed: 16398652]

10. Rey E, Kahn SR, David M, Shrier I. Thrombophilic disorders and fetal loss: a metaanalysis. Lancet. 2003; 361:901-908. [PubMed: 12648968]

11. Rodger MA, Betancourt MT, Clark P, Lindqvist PG, Dizon-Townson D, Said J, et al. The association of factor $\mathrm{V}$ Leiden and prothrombin gene mutation and placenta-mediated pregnancy complications: a systematic review and meta-analysis of prospective cohort studies. PLoS Med. 2010; 7(6):e1000292. [PubMed: 20563311]

12. Kist WJ, Janssen NG, Kalk JJ, Hague WM, Dekker GA, De Vries JIP. Thrombophilias and adverse pregnancy outcome-A confounded problem! Thromb Haemost. 2008; 99:77-85. [PubMed: 18217138]

13. Ridker PM, Miletich JP, Hennekens CH, Buring JE. Ethnic distribution of factor V Leiden in 4047 men and women. Implications for venous thromboembolism screening. JAMA. 1997; 277(16): 1305-1307. [PubMed: 9109469]

14. Dilley A, Austin H, Hooper WC, El-Jamil M, Whitsett C, Wenger NK, et al. Prevalence of the prothrombin $20210 \mathrm{G}$ to A variant in blacks: infants, patients with venous thrombosis, patients with myocardial infarction, and control subjects. J Lab Clin Med. 1998; 132:452-455. [PubMed: 9851733] 
15. Dowling N, Beckman M, Manco-Johnson M, Hassell K, Philipp CS, Michaels LA, et al. The US Thrombosis and Hemostasis Centers pilot sites program. J Thromb Thrombolysis. 2007; 23:1-7. [PubMed: 17111206]

16. Heit JA, Beckman MG, Bockenstedt PL, Grant AM, Key NS, Kulkarni R, et al. Comparison of characteristics from white and black Americans with venous thromboembolism: A cross-sectional study. Am J Hematol. 2010; 85:467-471. [PubMed: 20575037]

17. Landi D, Beckman MG, Shah NR, Bockenstedt P, Grant AM, Heit JA, et al. Characteristics of abdominal vein thrombosis in children and adults. Thromb Haemost. 2013; 109(4):569-768. [PubMed: 23447024]

18. Miyakis S, Lockshin MD, Atsumi T, Branch DW, Brey RL, Cervera R, et al. International consensus statement on an update of the classification criteria for the definite diagnosis of antiphospholipid syndrome. J Thromb Haemost. 2006; 4:295-306. [PubMed: 16420554]

19. Redline RW. Thrombophilia and placental pathology. Clin Obstet Gynecol. 2006; 49:885-894. [PubMed: 17082683]

20. Rai R. Is miscarriage a coagulopathy? Curr Opin Obstet Gynecol. 2003; 15:265-268. [PubMed: 12858117]

21. Hassell KL. Population estimates of sickle cell disease in the US. Am J Prev Med. 2010; 38(4S):S512-S521. [PubMed: 20331952]

22. Gris JC, Quere I, Monpeyroux F, Mercier E, Ripart-Neveu S, Tailland ML. Case-control study of the frequency of thrombophilic disorders in couples with late foetal loss and no thrombotic antecedent (NOHA4). Thromb Haemost. 1999; 81:891-899. [PubMed: 10404763]

23. Many A, Elad R, Yaron Y, Eldor A, Lessing JB, Kupferminc MJ. Third-trimester unexplained intrauterine fetal death is associated with inherited thrombophilia. Obstet Gynecol. 2002; 99(1): 684-687. [PubMed: 11978272]

24. Arck PC, Rucke M, Rose M, Szekeres-Bartho J, Douglas AJ, Pritsch M, et al. Early risk factors for miscarriage: a prospective cohort study in pregnant women. Reprod Biomed Online. 2008; 17(1): 101-103. [PubMed: 18616898]

25. Dizon-Townson D, Miller C, Sibai B, Spong CY, Thom E, Wendel G Jr, et al. The relationship of the factor $\mathrm{V}$ Leiden mutation and pregnancy outcomes for mother and fetus. Obstet Gynecol. 2005; 106:517-524. [PubMed: 16135581]

26. Silver RM, Zhao Y, Spong CY, Sibai B, Wendel G, Wenstrom K, et al. Prothrombin gene G20210A mutation and obstetric complications. Obstet Gynecol. 2010; 115:14-20. [PubMed: 20027028]

27. Hira B, Pegoraro RJ, Rom L, Moodley J. Absence of factor V Leiden, thrombomodulin and prothrombin gene variants in black South African women with pre-eclampsia and eclampsia. BJOG. 2003; 110:327-328. [PubMed: 12628278]

28. Bates SM, Greer IA, Middeldorp S, Veenstra DL, Prabulos A-M, Vandvik PO. VTE, thrombophilia, antithrombotic therapy, and pregnancy, 9th edition: American College of Chest Physicians Evidence Based Clinical Practice Guidelines. Chest. 2012; 141(Suppl. 2):e691s-e736s. [PubMed: 22315276]

29. Lockwood C, Wendel G. Practice bulletin no 124: Inherited thrombophilias in pregnancy. Obstet Gynecol. 2011; 118(3):730-740. [PubMed: 21860314] 
Table 1

Characteristics of Study Population with Adverse Pregnancy Outcomes by Race $(\mathrm{N}=409)$.

\begin{tabular}{llll}
\hline Characteristics & White $(\mathbf{N}=\mathbf{3 4 3})$ & Black $(\mathbf{N}=\mathbf{6 6})$ & p-value \\
\hline Age $^{*}$ (in years) mean $\pm \mathrm{SD}$ & $39.1 \pm 11.8$ & $33.8 \pm 10.4$ & $<0.01$ \\
$\mathrm{BMI}^{*}\left(\mathrm{~kg} / \mathrm{m}^{2}\right)$ mean $\pm \mathrm{SD}$ & $29.1 \pm 11.1$ & $31.9 \pm 9.6$ & 0.07 \\
Smoking $^{*} \mathrm{~N}(\%)$ & $53(15.5)$ & $9(13.6)$ & 0.71 \\
$\mathrm{BMI}^{* *}$ non-pregnant N $(\%)$ & $(\mathrm{N}=246)$ & $(\mathrm{N}=29)$ & \\
\hline$<25$ & $90(36.6)$ & $4(13.8)$ & 0.01 \\
$\geq 25$ & $156(63.4)$ & $25(86.2)$ & \\
\hline
\end{tabular}

* At enrollment into registry.

** $\mathrm{N}$ is different because of missing values. 
Table 2

Adverse Pregnancy Outcomes of Study Population by Race $(\mathrm{N}=409)$.

\begin{tabular}{llrrr}
\hline Adverse Pregnancy Outcomes & White $(\mathbf{N}=\mathbf{3 4 3})$ & & Black $(\mathbf{N}=\mathbf{6 6})$ & p-value \\
\cline { 2 - 2 } & $\mathbf{N}(\boldsymbol{\%})$ & & $\mathbf{N}(\%)$ & \\
\hline First Trimester Loss & $221(64.4)$ & & $39(59.1)$ & 0.41 \\
Second Trimester Loss & $75(21.9)$ & & $22(33.3)$ & 0.05 \\
Third Trimester Loss & $36(10.5)$ & & $10(15.2)$ & 0.27 \\
Any Pregnancy Loss & $313(91.3)$ & & $63(95.5)$ & 0.25 \\
Recurrent Pregnancy Loss & $159(46.4)$ & $28(42.4)$ & 0.56 \\
Intrauterine Growth Restriction & $11(3.2)$ & $2(3.0)$ & 1.00 \\
Preterm delivery & $27(7.9)$ & $3(4.6)$ & 0.45 \\
Preeclampsia & $20(5.8)$ & 0 & 0.06 \\
Placental Abruption & $17(5.0)$ & $4(6.1)$ & 0.76 \\
\hline
\end{tabular}


Table 3

Thrombophilia in Study Population with Adverse Pregnancy Outcomes by Race $(\mathrm{N}=409)$.

\begin{tabular}{lcrrr}
\hline Thrombophilia & White $(\mathbf{N}=\mathbf{3 4 3})$ & & Black $(\mathbf{N}=\mathbf{6 6})$ & p-value \\
\cline { 2 - 2 } \cline { 5 - 5 } & $\mathbf{N}(\%)$ & & $\mathbf{N}(\%)$ & \\
\hline Factor V Leiden & $65(19.0)$ & & $2(3.0)$ & $<0.01$ \\
Prothrombin gene mutation & $14(4.1)$ & & 0 & 0.14 \\
Protein C deficiency & $4(1.2)$ & & $2(3.0)$ & 0.25 \\
Protein S deficiency & $20(5.8)$ & & $10(15.2)$ & 0.02 \\
Antithrombin deficiency & $5(1.5)$ & & $4(6.0)$ & 0.04 \\
Antiphospholipid Syndrome & $60(17.5)$ & & $7(10.6)$ & 0.17 \\
Any Thrombophilia & $151(44.0)$ & & $20(30.3)$ & 0.04 \\
\hline
\end{tabular}


Table 4

History of Thrombosis in Study Population with Adverse Pregnancy Outcomes by Race $(\mathrm{N}=409)$.

\begin{tabular}{|c|c|c|c|}
\hline \multirow[t]{2}{*}{ History of Thrombosis } & \multirow{2}{*}{$\frac{\text { White }(\mathrm{N}=343)}{\mathrm{N}(\%)}$} & \multirow{2}{*}{$\frac{\text { Black }(N=66)}{N(\%)}$} & \multirow[t]{2}{*}{ p-value } \\
\hline & & & \\
\hline Recurrent VTE & $69(20.1)$ & $7(10.6)$ & 0.07 \\
\hline Idiopathic VTE* & $80(23.3)$ & $12(18.2)$ & 0.36 \\
\hline Pregnancy related VTE & $35(10.2)$ & $12(18.2)$ & 0.06 \\
\hline Post-surgery VTE & $37(10.8)$ & $1(1.5)$ & 0.02 \\
\hline Trauma related VTE & $12(3.6)$ & 0 & 0.23 \\
\hline Hormonal associated VTE ${ }^{* *}$ & $25(7.3)$ & $2(3.0)$ & 0.28 \\
\hline Any VTE & $146(42.6)$ & $25(37.6)$ & 0.48 \\
\hline Stroke & $28(8.2)$ & $3(4.6)$ & 0.45 \\
\hline Myocardial Infarction & $10(2.9)$ & 0 & 0.38 \\
\hline Not associated with surgery, tr & na, cancer, infe & , or hormone the & rapy. \\
\hline
\end{tabular}


Table 5

Comorbidities by Race in Study Population with Adverse Pregnancy Outcomes (N = 409).

\begin{tabular}{lrrrr}
\hline Comorbidities & White $(\mathbf{N}=\mathbf{3 4 3})$ & & Black $(\mathbf{N}=\mathbf{6 6})$ & p-value \\
\cline { 2 - 2 } & $\mathbf{N}(\boldsymbol{\%})$ & & $\mathbf{N}(\%)$ & \\
\hline Diabetes & $15(4.4)$ & $3(4.6)$ & 1.00 \\
Hypertension & $39(11.4)$ & $17(25.8)$ & $<0.01$ \\
Cancer & $19(5.5)$ & 0 & 0.05 \\
Autoimmune Disease & $69(20.1)$ & $15(22.7)$ & 0.63 \\
Sickle Cell Disease & 0 & $3(4.6)$ & $<0.01$ \\
\hline
\end{tabular}


Table 6

Family History by Race in Study Population with Adverse Pregnancy Outcomes (N = 409).

\begin{tabular}{lcccc}
\hline Family History & White $(\mathbf{N}=\mathbf{3 4 3})$ & & Black $(\mathbf{N}=\mathbf{6 6})$ & p-value \\
\cline { 2 - 2 } \cline { 5 - 5 } & $\mathbf{N}(\%)$ & & $\mathbf{N}(\%)$ & \\
\hline Adverse Pregnancy Outcome & $5(1.5)$ & & $1(1.5)$ & 1.00 \\
Thrombophilia & $20(5.8)$ & & 0 & 0.06 \\
Venous Thromboembolism & $74(21.6)$ & & $5(7.6)$ & $<0.01$ \\
Stroke/MI & $40(11.7)$ & & 0 & $<0.01$ \\
Any Family History & $107(31.2)$ & & $6(9.1)$ & $<0.01$ \\
\hline
\end{tabular}

